\title{
Microbial Translocation in Chronic Liver Diseases
}

\author{
Marilia Rita Pinzone, ${ }^{1}$ Benedetto Maurizio Celesia, ${ }^{1}$ \\ Michele Di Rosa, ${ }^{1}$ Bruno Cacopardo, ${ }^{1}$ and Giuseppe Nunnari ${ }^{1,2}$ \\ ${ }^{1}$ Division of Infectious Diseases, Department of Clinical and Molecular Biomedicine, University of Catania, 95125 Catania, Italy \\ ${ }^{2}$ Department of Microbiology and Immunology, Jefferson Medical College, Thomas Jefferson University, Philadelphia, PA 19107, USA
}

Correspondence should be addressed to Marilia Rita Pinzone, marilia.pinzone@virgilio.it

Received 24 April 2012; Accepted 18 June 2012

Academic Editor: Daniel Douek

Copyright (C) 2012 Marilia Rita Pinzone et al. This is an open access article distributed under the Creative Commons Attribution License, which permits unrestricted use, distribution, and reproduction in any medium, provided the original work is properly cited.

The intestinal microflora is not only involved in the digestion of nutrients, but also in local immunity, forming a barrier against pathogenic microorganisms. The derangement of the gut microflora may lead to microbial translocation, defined as the passage of viable microorganisms or bacterial products (i.e., LPS, lipopeptides) from the intestinal lumen to the mesenteric lymph nodes and other extraintestinal sites. The most recent evidence suggests that microbial translocation (MT) may occur not only in cirrhosis, but also in the early stage of several liver diseases, including alcoholic hepatopathy and nonalcoholic fatty liver disease. Different mechanisms, such as small intestinal bacterial overgrowth, increased permeability of intestinal mucosa, and impaired immunity, may favor MT. Furthermore, MT has been implicated in the pathogenesis of the complications of cirrhosis, which are a significant cause of morbidity and mortality in cirrhotic subjects. Therapeutic strategies aiming at modulating the gut microflora and reducing MT have focused on antibiotic-based options, such as selective intestinal decontamination, and nonantibioticbased options, such as prokinetics and probiotics. In particular, probiotics may represent an attractive strategy, even though the promising results of experimental models and limited clinical studies need to be confirmed in larger randomized trials.

\section{Introduction}

The intestinal microflora is a complex ecosystem, consisting of more than 500 microbial species, that are involved in the digestion of nutrients and the production of vitamins and short-chain fatty acids; furthermore, the gut microflora plays a role in local immunity, forming a barrier against pathogens, together with the intestinal mucosa [1]. The derangement of the gut microflora and increased microbial translocation (MT) have been widely described in advanced liver disease and associated with the pathogenesis of the complications of cirrhosis [2]; moreover, recent lines of evidence suggest the intestinal microflora to be directly implicated in the induction and progression of liver damage in several chronic liver diseases, including alcoholic and nonalcoholic steatohepatitis, two common causes of cirrhosis [3-5].
Here, we review current concepts regarding the pathogenesis of MT, its role in liver diseases and the potentialities of therapeutic strategies based on the modulation of intestinal flora (i.e. probiotics).

\section{Microbial Translocation in Cirrhosis}

Microbial translocation (MT) is defined as the migration of viable microorganisms or bacterial endotoxins (i.e., bacterial lipopolysaccharide (LPS), peptidoglycan, and lipopeptides) from the intestinal lumen to the mesenteric lymph nodes (MLN) and other extraintestinal sites [6, 7]. Gramnegative members of the Enterobacteraceae family (such as Escherichia coli and Klebsiella spp.), enterococci, and other streptococci species are the most effective at bacterial translocation to MLN, across even histologically normal intestinal mucosa $[8,9]$. On the contrary, anaerobic species 
only rarely translocate and they have been reported to limit the growth of aerobic species with higher translocation potentialities [10].

Increased MT has been described both in experimental animal models of cirrhosis and in cirrhotic patients. In animal studies, the prevalence of MT, defined as a positive bacteriological culture from surgically removed MLN, was around $50 \%$ in cirrhotic rats with ascites [11] and up to $80 \%$ in cirrhotic rats with spontaneous bacterial peritonitis (SBP) [12-14]. In humans, few studies are available, because of the difficulty in detecting MT to MLN and the lack of widely applicable noninvasive markers of MT. However, MT seems to occur more frequently in Child $\mathrm{C}$ cirrhotic patients (about $30 \%$ of positive MLN cultures), in comparison with Child B and A cirrhotic patients ( $8 \%$ and 3\%, resp.) [15]; in addition, levels of tumour necrosis factor (TNF)- $\alpha$ were found to be higher in MLN of cirrhotic patients than in controls and to correlate with Child-Pugh score and to the risk of developing bacterial infections during the first month after transplant [16].

Detection of bacterial deoxyribonucleic acid (bactDNA) in blood and ascites using the polymerase chain reaction (PCR) has been proposed as a sensitive surrogate marker of MT [17-19]. Such et al. [17] detected the presence of bactDNA (mainly E. coli) simultaneously in blood and ascites in as many as $32 \%$ of patients with advanced cirrhosis and sterile nonneutrocytic ascitic fluid. Of importance, bactDNA sequence similarity in blood and ascites suggested a shared origin, from a common MT event. Unfortunately, there was no correlation between the severity of liver disease and the detection of bactDNA in body fluids, so that the clinical impact of molecular methods to detect MT remains to be established.

\subsection{Pathogenesis of Microbial Translocation. Cirrhosis may} lead to MT via different mechanisms, including small intestinal bacterial overgrowth (SIBO), disturbance of luminal factors, increased permeability of intestinal mucosa, and impaired immunity. These factors are summarized in Figure 1.

SIBO. SIBO has been shown to frequently occur in the setting of chronic liver diseases and to be related to the degree of hepatic dysfunction [20]. The diagnosis of SIBO is based on the use of glucose breath hydrogen tests [21, 22] or quantitative culture of jejunal aspirates $[20,23]$. The limited sensitivity of breath tests [24] may explain the lower prevalence rates of SIBO (about $30-38 \%$ versus $48-73 \%$ ) found when using breath tests $[21,22]$ rather than jejunal colony counts $[23,24]$ to detect bacterial overgrowth.

A number of explanations may account for SIBO, including hypochlorhydrosis, malnutrition, and intestinal hypodysmotility [24-26]. The pathogenesis of small intestinal hypomotility in cirrhosis is multifactorial, as a result of increased adrenergic activity, enhanced nitric oxide (NO) production, and structural intestinal damage, due to oxidative stress and portal hypertension [20, 27]. Of note, SIBO itself may further compromise intestinal motility [28, 29], thus creating a vicious cycle that amplifies bacterial overgrowth. In animals, the administration of prokinetics, like cisapride $[23,30]$, and $\beta$-adrenergic blockers, like propanolol [31], has been reported to reduce SIBO and MT; in clinical practice, a six-month trial with cisapride showed decreased orocaecal transit time and SIBO elimination in $80 \%$ of patients with SIBO at baseline [23, 32]. Unfortunately, cisapride has been withdrawn from use in some countries because of potential for cardiac arrhythmia.

Disturbance of Luminal Factors. Several luminal factors, such as bile acids, secretory immunoglobulin A, mucins, defensins, lysozyme, and phospholipase A2, physiologically contribute to the intestinal barrier against MT. Bile acids inhibit bacterial overgrowth, especially of anaerobic species; moreover, the absence of bile in the intestine has been shown to promote MT [33]. In cirrhosis, the reduced secretion of bile acids may favor SIBO and MT. Of interest, oral administration of conjugated bile acids, cholylsarcosine, and cholylglycine has been reported to reduce intestinal bacterial content and to decrease the rate of MT in ascitic cirrhotic rats [34]. Further studies should evaluate the potential benefits of bile acids in humans.

Impaired Immunity. Cirrhosis is accompanied by several abnormalities of both systemic and local immune system. The reticulo-endothelial system (RES), whose activities are mainly located in the liver (Kupffer cells), is the main defense against bacteremia; in cirrhosis, phagocytic activity of Kupffer cells may be impaired and the presence of portosystemic shunts bypassing the liver (thereby escaping the action of the RES) may explain the failure to clear not only portal or systemic bacteria, but also endotoxins and cytokines [35]. In cirrhotic subjects, serum complement levels have been reported to be low [36, 37] and to independently predict the risk of infections and mortality [37]. Cirrhosis is also accompanied by a decrease in bactericidal activity by monocytes and neutrophils [38, 39]. An increased number of intraepithelial lymphocytes with markedly impaired proliferative activity and capacity to produce interferon- $\gamma$ have been reported in a murine model of cirrhosis and correlated with increased MT [40]. Considering the crucial role of intestinal immune cells in regulating the interplay between the host and gut flora, it can be assumed that the derangement of local immunity may allow translocated bacteria to escape from MLN and to reach systemic blood and other extraintestinal sites.

Increased Permeability. Structural and functional changes in intestinal mucosa may increase its permeability, contributing to the development of MT. Structural abnormalities, whose most important determinant appears to be portal hypertension, include vascular congestion, thickened muscularis mucosa, fibromuscular proliferation, and a reduced villus/crypt ratio [41]. In addition, ultrastructural abnormalities in the epithelial layer of small intestine specimens of cirrhotic subjects have been described [42]. In experimental cirrhosis, oxidative damage of the intestinal mucosa has 


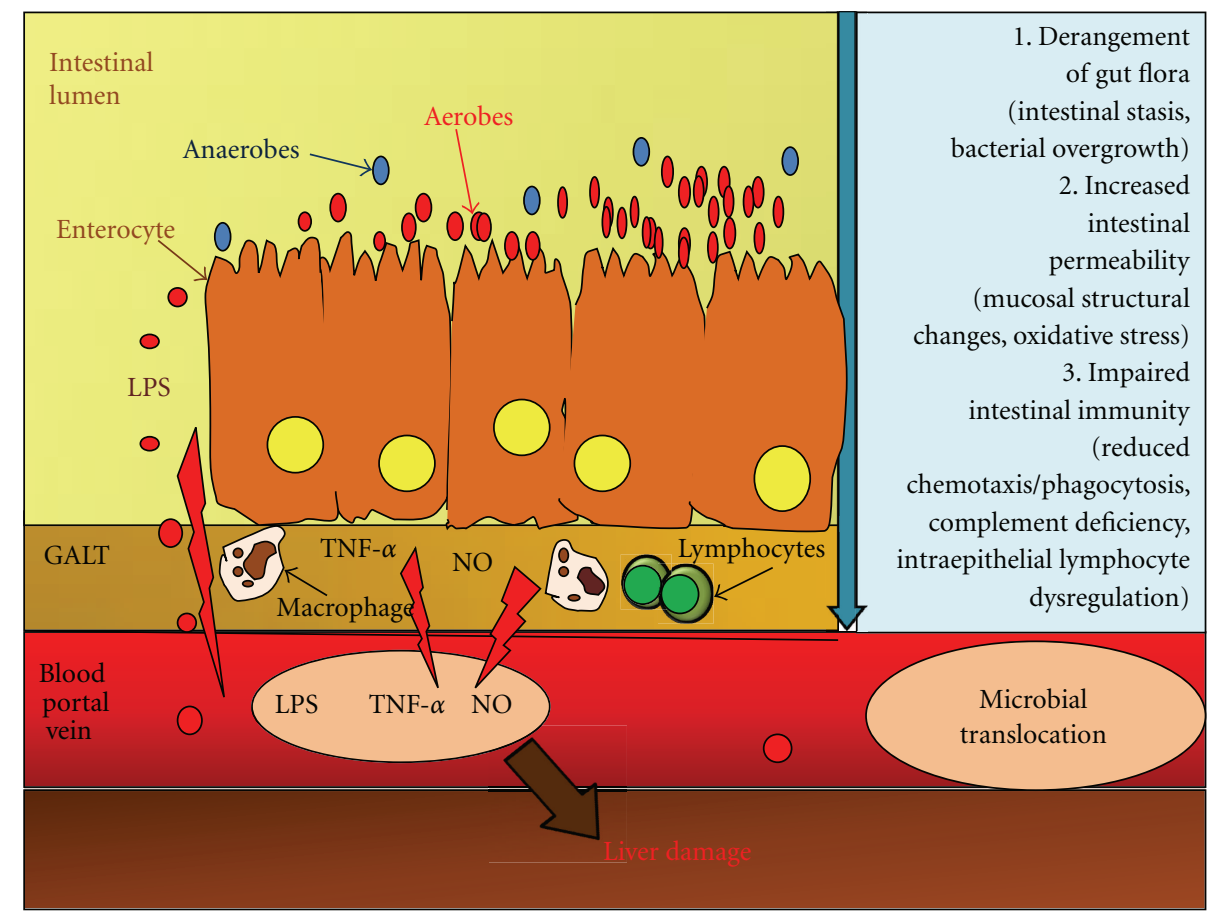

FIGURE 1: Mechanisms of microbial translocation in chronic liver diseases. LPS: lipopolysaccharide; NO: nitric oxide; GALT: gut-associated lymphatic tissue; TNF- $\alpha$; tumour necrosis factor.

been shown to cause lipid peroxidation of the brush border membranes and abnormal intestinal transport [43, 44]. Most functional studies, usually dual sugar absorption tests, have found increased intestinal permeability in patients with advanced liver disease [45-48]. Increased permeability is likely to occur via a paracellular route. In humans, morphologically intact tight junctions at the apical pole of enterocytes have been reported in a cohort of clinically stable cirrhotic patients with no prior history of infection with gut-derived bacteria [42], but it remains to be established whether tight junctions are intact in cirrhotic patients with a history of infection with enteric bacteria. Notably, dilatation of the intercellular space below tight junctions has been documented in patients with cirrhosis [32] and, more importantly, NO, whose role in cirrhosis is discussed below, has been shown to reversibly dilate tight junctions, to destroy the cytoskeleton, and to inhibit the formation of adenosine triphosphate in cultured intestinal epithelial cells [49].

\subsection{Not Only Microbes: Endotoxins and Cytokines in Cirrhosis.} As previously stated, MT does not only refer to the passage of viable bacteria, but also of microbial products, across the gut mucosa, thus causing the production of proinflammatory cytokines and vasoactive mediators. Patients with cirrhosis have been reported to have increased circulating levels of endotoxin (LPS), a cell wall component of Gramnegative bacteria $[50,51]$; MT, as well as reduced hepatic clearance, may be responsible for the spill-over of intestinal endotoxin into the systemic circulation. In fact, endotoxemia is significantly more frequent in cirrhotic rats with MT than in cirrhotic animals without MT [52]. Furthermore, MT itself has been reported to make the gut a "cytokinereleasing organ", even in the absence of portal or systemic bacteremia [53, 54]. Endotoxin-primed macrophages release high levels of TNF- $\alpha$ in experimental models of liver damage [55-57]. In rats, TNF- $\alpha$ levels in MLN have been shown to be higher in presence of MT and to correlate with TNF$\alpha$ plasma levels [58]; in humans, as previously reported, elevated levels of TNF- $\alpha$ in MLN of cirrhotic subjects have been found and significantly correlated with those detected in the blood [16]. The overproduction of proinflammatory cytokines has been associated with elevated plasma levels of LPS-binding protein (LBP), which is synthesized in the liver in response to endotoxin and promotes the binding of endotoxin to the CD14/Toll-like receptor 4 (TLR4) receptor complex [59]. Based on these observations, endotoxemia has been proposed as a major cause of the proinflammatory state in cirrhotic subjects [60-62]. However, other studies have failed to show a significant association between circulating endotoxin and proinflammatory cytokines levels [63-65]. Moreover, contrary to previous assumptions, Riordan et al. suggested to focus more on Gram-positive bacteria rather than Gram-negative ones: in fact, the authors described the upregulation of TLR2, responsible for signaling in response to Gram-positive microbial stimuli, but not of TLR4, on peripheral blood mononuclear cells (PBMCs) of cirrhotic subjects; in addition, TLR2 on PBMCs correlated with circulating levels of both TNF-a and soluble TNF receptors, while TLR4 did not [66]. 


\section{Taking a Step Back: Role of MT in the Induction and Progression of Liver Damage in Chronic Viral Hepatitis, Alcohol-Induced Hepatopathy, and NAFLD}

So far, we have focused on MT in the context of cirrhosis pathophysiology, but it must be taken into account that MT may work as a "trigger" in the induction and progression of various kinds of hepatic injury (i.e., inflammation, steatosis, fibrosis, and possibly cirrhosis) in several liver diseases, such as alcoholic, metabolic, and viral hepatitis. In fact, the derangement of the gut microflora and MT has been described even at the early stages of liver disease.

Alcoholic Hepatitis. Even if alcohol metabolism predominantly occurs in the liver, it is known that colonic bacteria are able to produce large amounts of acetaldehyde from ethanol [67-69]; acetaldehyde is responsible, in turn, of increased intestinal permeability and increased translocation of LPS to the portal vein and on to the liver [70]. In fact, plasma endotoxin levels have been shown to be higher than healthy controls not only in subjects with alcoholic cirrhosis, but also in patients with mild forms of alcoholic hepatitis [71, 72]. In the liver, the LPS/TLR4 pathway has been demonstrated to promote fibrogenesis, by sensitizing stellate cells to transforming growth factor- $\beta$ (TGF- $\beta$ )-induced signals and promoting TGF- $\beta$ release by Kupffer cells [73]. Experiments in rats [74] and clinical studies in humans [75-77] have demonstrated both quantitative and qualitative changes in the gut microflora of alcoholic subjects, in comparison with controls. In addition, ethanol-mediated oxidative stress appears to be an important mechanism that leads to gut leakiness and increased MT [78-81]. In particular, the overproduction of $\mathrm{NO}$ and its metabolite peroxynitrite (ONOO-) has been associated with the disruption of the intestinal epithelial layer. NO is synthesized from L-arginine by NOS. Three isoforms of NOS have been identified: neuronal (n)NOS, endothelial (e)NOS, and inducible (i)NOS. While nNOS and eNOS are considered protective for the intestinal mucosa, iNOS may be induced by bacterial products and cytokines and it is believed to significantly contribute to local inflammation and hyperpermeability [82], as confirmed by the observation of reduced alcohol-induced gut leakiness when administering iNOS inhibitors [78]. Furthermore, alcohol has been reported to dysregulate immune responses, suppressing natural killer cell activity, antibody-dependent cell-mediated cytotoxicity, and T-cell-dependent antibody responses, thus globally increasing the host susceptibility to pathogenic bacteria of the gut $[83,84]$.

Viral Hepatitis. Several studies reported elevated LPS levels in the context of chronic viral hepatitis by hepatitis $C$ virus $(\mathrm{HCV})$ and hepatitis $\mathrm{B}$ virus (HBV) $[85,86]$. In a recent work, Sandler et al. [86] have retrospectively investigated whether the extent and progression of liver disease in patients with chronic HBV or HCV infection were associated with MT and the subsequent local and systemic inflammation. HCV- and HBV-infected individuals had higher plasma levels of LPS, soluble (s)CD14 (produced upon LPS activation of monocytes), and interleukin-6, in comparison with controls. Levels of sCD14 correlated with markers of hepatic inflammation and fibrosis and were significantly higher in subjects with severe fibrosis at presentation, in comparison with those having minimal fibrosis $(P=0.01)$. Importantly, sCD14 was significantly higher in progressors than nonprogressors $(P=0.003)$; moreover, an increase in sCD14 of $1.0 \times 10^{6} \mathrm{pg} / \mathrm{ml}$ was associated with an odds ratio of disease progression of $3.7(P=0.007)$, with no changes after adjustment for other prognostic factors. Of note, elevated sCD14 levels, but not LPS itself, predicted clinical outcome.

Recent lines evidence coming from studies on HIVHCV coinfected cohorts have reported a similar correlation between sCD14 and the severity of liver disease [87, 88]. In addition, Marchetti et al. [87] have recently investigated whether baseline MT (as assessed by measuring LPS levels) or host response to MT ( $\mathrm{sCD} 14$ ) could be predictive of early virological response (EVR: HCV-RNA <50 IU/mL at week 12 of therapy or $\geq 2 \log 10$ reduction from baseline after 12 weeks of therapy) and sustained virological response (SVR: HCVRNA $<50 \mathrm{IU} / \mathrm{mL} 24$ weeks after end of therapy) to HCV treatment. In the univariate model, the authors found that lower sCD14 levels were predictive of both EVR and SVR, while LPS were not; however, sCD14 lost its independent predictive value in the multivariable model, thus limiting the possibility to use it in clinical practice as measure to a priori include/exclude patients from treatment.

Metabolic Hepatitis. Nonalcoholic fatty liver disease (NAFLD) is the most common cause of liver disease in industrialized countries. It usually develops in the setting of obesity and insulin resistance and comprises a continuum of disease ranging from simple steatosis to steatohepatitis (NASH) to cirrhosis. Obesity has been associated with changes in the gut microflora [4] and increased intestinal permeability [89-91]. In subjects with NAFLD, the prevalence of SIBO has also described as higher than controls [91, 92]. A high-fat diet has been reported not only to increase intestinal translocation of endotoxin in mice (the so-called metabolic endotoxemia), but also to reduce enteric Bifidobacteria [93, 94], a group of bacteria that have been shown to lower intestinal LPS levels and to improve mucosal barrier function [95]. Furthermore, mice chronically receiving a continuous low rate of LPS, as well as high-fat diet-fed mice, developed insulin resistance, had high circulating levels of proinflammatory cytokines and increased liver triglyceride content. These effects were completely blunted in CD14 mutant mice [94]. Other studies have shown that even the early stages of fructose-induced NAFLD (e.g., steatosis) are associated with increased intestinal translocation of endotoxin and expression of TNF- $\alpha$ in the liver, whereas TNF- $\alpha$ expression and steatosis were markedly lower in the liver of fructose-fed mice treated with antibiotics or TLR-4-mutant mice $[96,97]$. In humans with NAFLD, TNF- $\alpha$ expression was reported to be increased too $[92,98]$. These data globally support the idea that the LPS/CD14 system has a pivotal role in the induction of the 
low tone inflammatory status of metabolic disease, setting the threshold of insulin sensitivity and the onset of diabetes and obesity.

\section{Taking a Step Forward: Role of MT in the Pathogenesis of the Complications of Cirrhosis}

The gut microflora has been shown to contribute to the pathogenesis of the complications of cirrhosis, including the development of spontaneous bacterial infections and worsening of the hyperdynamic circulatory state (HCS), a hemodynamic perturbation that may lead to ascites, esophageal variceal growth and hepatorenal syndrome.

Spontaneous bacterial infections (i.e., SBP, empyema, and bacteremia) have an incidence rate of $15 \%-47 \%$ in cirrhotic subjects [99-103] and are mainly caused by Gramnegative bacteria, even though the incidence of infections from Gram-positive cocci has increased in recent series, as a consequence of the use of chronic antibiotic prophylaxis [104-106] and more frequent therapeutic invasive procedures [102]. Mortality is significantly higher in cirrhotic patients developing an infection $[101,103]$. SBP, an infection of ascitic fluid typically with a single bacterial species, in the absence of any other primary intra-abdominal source, has been shown to be present in up to $23 \%$ of cirrhotic patients with ascites undergoing paracentesis [107]. An increased prevalence of SBP has been described in patients with SIBO [108]; conversely, subjects with SBP have a higher prevalence of SIBO than those without SBP [109]. Animal studies have established a causal link between MT and SBP [14]; in humans, this relationship is supported by the observation that selective intestinal decontamination (SID) by the use of oral nonabsorbable antibiotics is effective in decreasing the incidence of spontaneous bacterial infections in cirrhotic subjects [110-113].

MT has been postulated as an important mechanism in the development of the cirrhotic HCS, which is characterized by low vascular resistance, low mean arterial pressure, and by increased heart rate, cardiac output, and regional blood flow. The HCS is mainly due to splanchnic and systemic vasodilatation, which result in "underfilling" of the arterial system and subsequent activation of compensatory mechanisms (i.e., renin-angiotensin aldosterone, sympathetic nervous system, and antidiuretic hormone), which are responsible for increased plasma volume and cardiac output. The HCS contributes to portal hypertension and many of the complications of cirrhosis $[2,114]$. NO appears to be the key vasodilator responsible for the haemodynamic abnormalities of cirrhosis [115]. It has been reported that gut-derived endotoxins and the resultant increase in inflammatory cytokines are able to induce the expression of iNOS in vessel walls, causing NO overproduction, vasodilatation, and HCS [116]. Endotoxemia has been shown to correlate with serum NO-metabolite levels $[117,118]$; moreover, HCS appears to be more marked in patients with cirrhosis and ascites having high levels of LBP [59]. The role of cytokines, specifically TNF-a, in the development of the HCS is evidenced by studies showing that TNF-a inhibitors ameliorate HCS in cirrhotic rats [119]. The importance of the gut microflora in inducing the production of vasoactive mediators has suggested to use SID as a strategy to decrease bacterial overgrowth and MT, in attempts to ameliorate the HCS. Patients treated with a 4-week course of oral norfloxacin demonstrated improvement in biologic and hemodynamic end points, with trends toward reduction in cardiac output, improvements in mean arterial blood pressure and reduced MT $[59,120]$.

A growing amount of data suggests that bacterial infections may work as an important trigger for variceal bleeding in patients with cirrhosis $[121,122]$, possibly as a consequence of enhanced activation of hepatic stellate cells, which may increase intrahepatic vascular resistance and portal hypertension and precipitate the coagulopathy that results from prostacyclin-related inhibition of platelet aggregation, consumption of clotting factors by the extrinsic coagulation pathway and reduction of endogenous heparinoids [122-124]. Conversely, variceal haemorrhage predisposes to bacterial infections with gut-derived microflora, thus creating a vicious cycle between gastrointestinal bleeding and infections, which significantly increases the mortality rates in this group of patients [125-127].

MT may also participate in the pathogenesis of hepatic encephalopathy (HE). HE is associated with the presence of portal and systemic shunts and the failure of the liver to clear ammonia and other toxic products derived from the gut $[128,129]$. Ammonia is produced in both the small bowel (from the effects of glutaminase on glutamine) and large intestine (from urease activity of the colonic flora). Colonic bacteria may also produce gamma-amino-butyric acid (GABA) and benzodiazepine (BZD)-like substances $[130,131]$, which have been implicated in the development of HE $[132,133]$. The role of the gut microflora in the pathogenesis of $\mathrm{HE}$ is supported by the observation that total colectomy is effective in reducing baseline and proteininduced ammonia production [134], reversing cases of HE which had not been responsive to medical treatment [135]. Nevertheless, HE may recur, probably as a consequence of the colonization of the small bowel [136].

\section{Searching for Effective Therapeutic Options: Selective Intestinal Decontamination and Probiotics}

Modulation of the intestinal microflora through the use of selective intestinal decontamination (SID) and probiotics has been proposed as an emerging therapeutic strategy in the management of chronic liver diseases.

SID. Long-term use of norfloxacin, a poorly absorbed quinolone, has been reported to markedly reduce the count of intestinal aerobic Gram-negative bacilli, but not Grampositive cocci or anaerobic bacteria [112]. In cirrhotic animals, some studies have shown that the use of oral norfloxacin or trimethoprim/sulfamethoxazole was associated with a decrease in BT $[137,138]$, while other studies 
have not [139]. In the clinical setting, a double blind, placebo-controlled trial evaluating the long-term efficacy of norfloxacin in cirrhotic patients who had survived a previous episode of SBP, found a significant reduction of the risk of SBP recurrence in the treated group (20\% versus $68 \%)$ at one year of followup [112]. In cirrhotic patients with low ascitic fluid protein concentrations, long-term prophylactic treatment with norfloxacin was effective even in the prevention of the first episode of SBP, but a major concern of long-term antibiotic prophylaxis is the development of quinolone-resistant infections [140]. Of interest, primary prophylaxis with norfloxacin has been associated with higher rates of trimethoprim-sulfamethoxazole resistance and increased incidence of infections with Gram-positive bacteria, including severe hospital-acquired staphylococcal infections $[102,106,141]$. On the basis of these observations, it is crucial to define non-antibiotic strategies to reduce MT and prevent infections.

Probiotics. Probiotics, commonly lactose-fermenting Lactobacilli and Bifidobacteria, have been reported to stabilize mucosal barrier function and modulate the gut microflora, limiting the growth of pathogenic bacteria, by acidifying the gut lumen, competing for nutrients, and producing antimicrobial substances [95, 142].

In vitro, the probiotic Lactobacillus casei $G G$ has been shown to inhibit the translocation of E. coli in a dosedependent manner [143]; however, in vivo lines of evidence are controversial. Some studies performed in cirrhotic rats have failed to find significant differences in MT rates between cirrhotic animals receiving Lactobacilli and untreated controls $[144,145]$. On the other hand, Forsyth et al. described reduced gut leakiness and less severe alcoholic steatohepatitis in alcohol plus Lactobacillus GG-fed rats, in comparison with alcohol-fed rats [146]. A combination of Lactobacillus johnsonii LA1 and antioxidants was effective in reducing MT, oxidative damage, and endotoxemia in rats with $\mathrm{CCl}_{4}$-induced cirrhosis; unfortunately, the authors did not include a group receiving Lactobacillus johnsonii LA1 alone [147]. In experimental models of NAFLD, it has been reported that mice treated with VSL\#3 (containing Streptococcus thermophilus, B. breve, B. longum, B. infantis, L. acidophilus, L. plantarum, L. casei, and L. bulgaricus) had lower liver inflammation, serum alanine aminotransferase (ALT), and hepatic total fatty acid content in comparison with controls [148]. Similarly, a recent work of Xu et al. has shown reduced fat accumulation in the liver of highfat diet-fed rats receiving Bifidobacterium longum and in those receiving Lactobacillus acidophilus, in comparison with high-fat diet-fed controls. Of interest, intestinal permeability was not affected by probiotics; furthermore, Bifidobacterium longum was more effective than Lactobacillus acidophilus in attenuating liver fat accumulation [149]. In high-fat dietfed mice, VSL\#3 administration has been associated with decreased hepatic steatosis and insulin resistance, as well as reduced expression of lipid peroxidation markers, TNF$\alpha$, iNOS, cyclooxygenase 2 , and matrix metalloproteinases (MMPs) [150, 151]; in another study, the use of VSL\#3 ameliorated hepatic fibrosis, by decreasing expression of procollagen and MMPs, but not steatosis or inflammation [152].

In humans, VSL\#3 administration has been reported to reduce oxidative stress in patients with NAFLD and alcoholic liver cirrhosis, but not chronic hepatitis C [153]. Cirrhotic subjects receiving Escherichia coli Nissle for 42 days showed a trend toward lower endotoxin levels and improvement in Child-Pugh score [154]; similar results were obtained by Liu et al. when administering a symbiotic compound (a mixture of lactic acid bacteria and fermentable fiber), Synbiotic 2000, to cirrhotic patients [155]. A significant reduction in Child-Pugh class occurred in $47 \%$ of patients receiving Synbiotic 2000 for 30 days, whereas this only occurred in $29 \%$ of patients randomized to fiber alone and $8 \%$ of patients on placebo. Of importance, stool analysis demonstrated the reduction of Gram-negative fecal flora; furthermore, Synbiotic 2000 was associated with a significant improvement of minimal hepatic encephalopathy (MHE) and decreased endotoxemia. On the basis of these observations, it is possible to hypothesize the beneficial role of symbiotics in modulating the gut flora and reducing MT, as confirmed by the lower circulating endotoxin levels found in symbiotic-treated subjects. Opposing results were recently reported in a study of Pereg et al., who failed to show any beneficial effect of probiotic administration in patients with compensated liver cirrhosis [156]. In this doubleblind placebo-controlled study, 36 patients were randomly assigned to receive probiotic capsules containing Lactobacillus acidophilus, Lactobacillus bulgaricus, Bifidobacterium lactis and Streptococcus thermophiles or placebo for 6 months. No differences in either clinical or laboratory parameters between the two groups were found; the small size of the study population, the reduced number of patients having a Child-Pugh class $>\mathrm{A}$, and the longer period of treatment may globally explain the different conclusions of this trial in comparison with those described above.

As refers to the use of probiotics for the prevention of infections, it has been reported that a symbiotic regimen including Lactobacillus plantarum and fermentable fiber was more effective than SID in reducing the incidence of bacterial infections in liver transplant recipients [157]. Analogously, a follow-up randomized double-blind trial in liver transplant recipients has shown the rate of postoperative bacterial infections to be significantly lower in subjects receiving a mixture of lactic acid bacteria and fermentable fiber, in comparison with fermentable fiber alone [158].

The effects of the prebiotic lactitol on the intestinal flora and plasma endotoxin levels have recently been evaluated in patients with chronic viral hepatitis [159]. Lactitol and lactulose are synthetic non-absorbable disaccharides, widely used in the treatment of HE; due to the lack of a suitable galactosidase in the upper part of the gastrointestinal tract, they are able to reach undigested the large bowel, where they are metabolized by colonic bacteria, generating organic acids [160]. The resulting lower $\mathrm{pH}$ may inhibit urease-producing intestinal bacteria and promote the growth of non-urease-producing lactobacilli [161]; on the basis of these observations, it is unsurprising the report by 
Chen et al. [159] of increased levels of beneficial bacteria, such as Bifidobacteria and Lactobacilli, in lactitol-receiving patients with $\mathrm{HCV}$, with a consensual decline in endotoxemia, in comparison with untreated controls.

In the setting of $\mathrm{HE}$, current approaches include the use of non-absorbable antibiotics (i.e. neomycin, paromomycin, metronidazole, or rifaximin) and non-absorbable disaccharides [162]. Probiotics appear to be a promising therapeutic option in the management of $\mathrm{HE}[155,163-$ 166]. In fact, some studies have shown that probiotics may positively modulate the gut microflora, reducing the amount of bacterial ammonia reaching the portal vein. The long-term oral administration of Enterococcus faecium SF 68 was at least as effective as lactulose in improving neurocognitive tests and reducing ammonia levels in patients with HE. Of importance, in this trial the improvement in mental status was maintained during the washout periods in probiotic-treated subjects, but not in lactulosetreated ones [163]. Similarly, cirrhotic patients with minimal hepatic encephalopathy receiving Bifidobacterium longum plus fructo-oligosaccharides for 3 months had a significant improvement in both biochemical and neuropsychological tests compared to controls [164].

\section{Conclusions}

The interaction between the gut microflora and the host may play a crucial role in the natural history of chronic liver diseases. In clinical practice, there is a need of surrogate markers of MT and non-antibiotic methods, which may positively modify the gut ecosystem and reduce the passage of bacteria and bacterial products through the gut. Considering the results coming from experimental models and limited clinical studies, probiotics are an attractive strategy, but they need further investigation in larger controlled clinical trials.

\section{References}

[1] M. C. Abt and D. Artis, "The intestinal microbiota in health and disease: the influence of microbial products on immune cell homeostasis," Current Opinion in Gastroenterology, vol. 25, no. 6, pp. 496-502, 2009.

[2] G. Garcia-Tsao and R. Wiest, "Gut microflora in the pathogenesis of the complications of cirrhosis," Best Practice and Research, vol. 18, no. 2, pp. 353-372, 2004.

[3] C. S. Schaffert, M. J. Duryee, C. D. Hunter et al., "Alcohol metabolites and lipopolysaccharide: roles in the development and/or progression of alcoholic liver disease," World Journal of Gastroenterology, vol. 15, no. 10, pp. 1209-1218, 2009.

[4] H. Tilg, A. R. Moschen, and A. Kaser, "Obesity and the microbiota," Gastroenterology, vol. 136, no. 5, pp. 1476-1483, 2009.

[5] P. D. Cani and N. M. Delzenne, "The role of the gut microbiota in energy metabolism and metabolic disease," Current Pharmaceutical Design, vol. 15, no. 13, pp. 15461558, 2009.

[6] R. Wiest and H. C. Rath, "Bacterial translocation in the gut," Bailliere's Best Practice and Research in Clinical Gastroenterology, vol. 17, no. 3, pp. 397-425, 2003.
[7] R. D. Berg and A. W. Garlington, "Translocation of certain indigenous bacteria from the gastrointestinal tract to the mesenteric lymph nodes and other organs in a gnotobiotic mouse model," Infection and Immunity, vol. 23, no. 2, pp. 403-411, 1979.

[8] E. K. Steffen, R. D. Berg, and E. A. Deitch, "Comparison of translocation rates of various indigenous bacteria from the gastrointestinal tract to the mesenteric lymph node," Journal of Infectious Diseases, vol. 157, no. 5, pp. 1032-1038, 1988.

[9] C. L. Wells, "Colonization and translocation of intestinal bacterial flora," Transplantation Proceedings, vol. 28, no. 5, pp. 2653-2656, 1996.

[10] C. L. Wells, M. A. Maddaus, C. M. Reynolds, R. P. Jechorek, and R. L. Simmons, "Role of anaerobic flora in the translocation of aerobic and facultatively anaerobic intestinal bacteria," Infection and Immunity, vol. 55, no. 11, pp. 26892694, 1987.

[11] G. Garcia-Tsao, F. A. Y. Lee, G. E. Barden, R. Cartun, and A. B. West, "Bacterial translocation to mesenteric lymph nodes is increased in cirrhotic rats with ascites," Gastroenterology, vol. 108, no. 6, pp. 1835-1841, 1995.

[12] J. M. Llovet, R. Bartoli, R. Planas et al., "Bacterial translocation in cirrhotic rats. Its role in the development of spontaneous bacterial peritonitis," Gut, vol. 35, no. 11, pp. 1648-1652, 1994.

[13] B. A. Runyon, S. Squier, and M. Borzio, "Translocation of gut bacteria in rats with cirrhosis to mesenteric lymph nodes partially explains the pathogenesis of spontaneous bacterial peritonitis," Journal of Hepatology, vol. 21, no. 5, pp. 792-796, 1994.

[14] J. M. Llovet, R. Bartolí, F. March et al., "Translocated intestinal bacteria cause spontaneous bacterial peritonitis in cirrhotic rats: molecular epidemiologic evidence," Journal of Hepatology, vol. 28, no. 2, pp. 307-313, 1998.

[15] I. Cirera, T. M. Bauer, M. Navasa et al., "Bacterial translocation of enteric organisms in patients with cirrhosis," Journal of Hepatology, vol. 34, no. 1, pp. 32-37, 2001.

[16] J. Genescà, R. Martí, F. Rojo et al., "Increased tumour necrosis factor $\alpha$ production in mesenteric lymph nodes of cirrhotic patients with ascites," Gut, vol. 52, no. 7, pp. 10541059, 2003.

[17] J. Such, R. Francés, C. Muoz et al., "Detection and identification of bacterial DNA in patients with cirrhosis and culturenegative, nonneutrocytic ascites," Hepatology, vol. 36, no. 1, pp. 135-141, 2002.

[18] P. Zapater, R. Francés, J. M. González-Navajas et al., “Serum and ascitic fluid bacterial DNA: a new independent prognostic factor in noninfected patients with cirrhosis," Hepatology, vol. 48, no. 6, pp. 1924-1931, 2008.

[19] R. Francés, C. Muñoz, P. Zapater et al., "Bacterial DNA activates cell mediated immune response and nitric oxide overproduction in peritoneal macrophages from patients with cirrhosis and ascites," Gut, vol. 53, no. 6, pp. 860-864, 2004.

[20] T. M. Bauer, H. Schwacha, B. Steinbrückner et al., "Small intestinal bacterial overgrowth in human cirrhosis is associated with systemic endotoxemia," American Journal of Gastroenterology, vol. 97, no. 9, pp. 2364-2370, 2002.

[21] C. Bode, R. Kolepke, K. Schafer, and J. Bode, "Breath hydrogen excretion in patients with alcoholic liver diseaseevidence of small intestinal bacterial overgrowth," Zeitschrift fur Gastroenterologie, vol. 31, no. 1, pp. 3-7, 1993. 
[22] C. Y. Yang, C. S. Chang, and G. H. Chen, "Small-intestinal bacterial overgrowth in patients with liver cirrhosis, diagnosed with glucose $\mathrm{H}_{2}$ or $\mathrm{CH}_{4}$ breath tests," Scandinavian Journal of Gastroenterology, vol. 33, no. 8, pp. 867-871, 1998.

[23] A. Pardo, R. Bartolí, V. Lorenzo-Zúniga et al., "Effect of cisapride on intestinal bacterial overgrowth and bacterial translocation in cirrhosis," Hepatology, vol. 31, no. 4, pp. 858-863, 2000.

[24] T. M. Bauer, H. Schwacha, B. Steinbrückner et al., "Diagnosis of small intestinal bacterial overgrowth in patients with cirrhosis of the liver: poor performance of the glucose breath hydrogen test," Journal of Hepatology, vol. 33, no. 3, pp. 382 386, 2000.

[25] K. Shindo, M. Machida, K. Miyakawa, and M. Fukumura, "A syndrome of cirrhosis, achlorhydria, small intestinal bacterial overgrowth, and fat malabsorption," American Journal of Gastroenterology, vol. 88, no. 12, pp. 2084-2091, 1993.

[26] A. M. Madrid, F. Cumsille, and C. Defilippi, "Altered small bowel motility in patients with liver cirrhosis depends on severity of liver disease," Digestive Diseases and Sciences, vol. 42, no. 4, pp. 738-742, 1997.

[27] R. Sadik, H. Abrahamsson, E. Björnsson, A. Gunnarsdottir, and P. O. Stotzer, "Etiology of portal hypertension may influence gastrointestinal transit time," Scandinavian Journal of Gastroenterology, vol. 38, no. 10, pp. 1039-1044, 2003.

[28] E. Husebye, P. M. Hellström, F. Sundler, J. Chen, and T. Midtvedt, "Influence of microbial species on small intestinal myoelectric activity and transit in germ-free rats," American Journal of Physiology, vol. 280, no. 3, pp. G368-G380, 2001.

[29] M. T. Liu, J. D. Rothstein, M. D. Gershon, and A. L. Kirchgessner, "Glutamatergic enteric neurons," Journal of Neuroscience, vol. 17, no. 12, pp. 4764-4784, 1997.

[30] S. C. Zhang, W. Wang, W. Y. Ren, B. M. He, K. Zhou, and W. N. Zhu, "Effect of cisapride on intestinal bacterial and endotoxin translocation in cirrhosis," World Journal of Gastroenterology, vol. 9, no. 3, pp. 534-538, 2003.

[31] M. Pérez-Paramo, J. Munoz, A. Albillos et al., "Effect of propranolol on the factors promoting bacterial translocation in cirrhotic rats with ascites," Hepatology, vol. 31, no. 1, pp. 43-48, 2000.

[32] A. M. Madrid, C. Hurtado, M. Venegas, F. Cumsille, and C. Defilippi, "Long-term treatment with cisapride and antibiotics in liver cirrhosis: effect on small intestinal motility, bacterial overgrowth, and liver function," American Journal of Gastroenterology, vol. 96, no. 4, pp. 1251-1255, 2001.

[33] M. M. Slocum, K. M. Sittig, R. D. Specian, and E. A. Deitch, "Absence of intestinal bile promotes bacterial translocation," American Surgeon, vol. 58, no. 5, pp. 305-310, 1992.

[34] V. Lorenzo-Zúñiga, R. Bartolí, R. Planas et al., "Oral bile acids reduce bacterial overgrowth, bacterial translocation, and endotoxemia in cirrhotic rats," Hepatology, vol. 37, no. 3, pp. 551-557, 2003.

[35] A. Rimola, R. Soto, F. Boro et al., "Reticuloendothelial system phagocytic activity in cirrhosis and its relation to bacterial infections and prognosis," Hepatology, vol. 4, no. 1, pp. 53$58,1984$.

[36] N. D. Finlayson, K. Krohn, M. H. Fauconnet, and K. E. Anderson, "Significance of serum complement levels in chronic liver disease," Gastroenterology, vol. 63, no. 4, pp. 653-659, 1972.

[37] C. Homann, K. Varming, K. Høgåsen et al., "Acquired C3 deficiency in patients with alcoholic cirrhosis predisposes to infection and increased mortality," Gut, vol. 40, no. 4, pp. 544-549, 1997.

[38] A. Hassner, Y. Kletter, M. Jedvab et al., "Impaired monocyte function in liver cirrhosis," The Lancet, vol. 1, no. 8111, pp. 329-330, 1979.

[39] I. A. Rajkovic and R. Williams, "Abnormalities of neutrophil phagocytosis, intracellular killing and metabolic activity in alcoholic cirrhosis and hepatitis," Hepatology, vol. 6, no. 2, pp. 252-262, 1986.

[40] T. Inamura, S. Miura, Y. Tsuzuki et al., "Alteration of intestinal intraepithelial lymphocytes and increased bacterial translocation in a murine model of cirrhosis," Immunology Letters, vol. 90, no. 1, pp. 3-11, 2003.

[41] V. Misra, S. P. Misra, M. Dwivedi, and S. C. Gupta, "Histomorphometric study of portal hypertensive enteropathy," American Journal of Clinical Pathology, vol. 108, no. 6, pp. 652-657, 1997.

[42] J. V. Such, J. V. Guardiola, J. de Juan et al., "Ultrastructural characteristics of distal duodenum mucosa in patients with cirrhosis," European Journal of Gastroenterology and Hepatology, vol. 14, no. 4, pp. 371-376, 2002.

[43] A. Ramachandran, R. Prabhu, S. Thomas, J. B. Reddy, A. Pulimood, and K. A. Balasubramanian, "Intestinal mucosal alterations in experimental cirrhosis in the rat: role of oxygen free radicals," Hepatology, vol. 35, no. 3, pp. 622-629, 2002.

[44] M. Chiva, C. Guarner, C. Peralta et al., "Intestinal mucosal oxidative damage and bacterial translocation in cirrhotic rats," European Journal of Gastroenterology and Hepatology, vol. 15, no. 2, pp. 145-150, 2003.

[45] M. J. Zuckerman, I. S. Menzies, H. Ho et al., "Assessment of intestinal permeability and absorption in cirrhotic patients with ascites using combined sugar probes," Digestive Diseases and Sciences, vol. 49, no. 4, pp. 621-626, 2004.

[46] S. Pascual, J. Such, A. Esteban et al., "Intestinal permeability is increased in patients with advanced cirrhosis," HepatoGastroenterology, vol. 50, no. 53, pp. 1482-1486, 2003.

[47] R. Cariello, A. Federico, A. Sapone et al., "Intestinal permeability in patients with chronic liver diseases: its relationship with the aetiology and the entity of liver damage," Digestive and Liver Disease, vol. 42, no. 3, pp. 200-204, 2010.

[48] V. Di Leo, C. Venturi, A. Baragiotta, D. Martines, and A. Floreani, "Gastroduodenal and intestinal permeability in primary biliary cirrhosis," European Journal of Gastroenterology and Hepatology, vol. 15, no. 9, pp. 967-973, 2003.

[49] A. L. Salzman, M. J. Menconi, N. Unno et al., "Nitric oxide dilates tight junctions and depletes ATP in cultured Caco2BBe intestinal epithelial monolayers," American Journal of Physiology, vol. 268, no. 2, pp. G361-G373, 1995.

[50] R. S. Lin, F. Y. Lee, S. D. Lee et al., "Endotoxemia in patients with chronic liver diseases: relationship to severity of liver diseases, presence of esophageal varices, and hyperdynamic circulation," Journal of Hepatology, vol. 22, no. 2, pp. 165172, 1995.

[51] L. M. Bigatello, S. A. Broitman, L. Fattori et al., "Endotoxemia, encephalopathy, and mortality in cirrhotic patients," American Journal of Gastroenterology, vol. 82, no. 1, pp. 1115, 1987.

[52] R. Wiest, G. Cadelina, S. Milstien, R. S. McCuskey, G. GarciaTsao, and R. J. Groszmann, "Bacterial translocation upregulates GTP-cyclohydrolase I in mesenteric vasculature of cirrhotic rats," Hepatology, vol. 38, no. 6, pp. 1508-1515, 2003. 
[53] M. R. Mainous, W. Ertel, I. H. Chaudry, and E. A. Deitch, "The gut: a cytokine-generating organ in systemic inflammation?" Shock, vol. 4, no. 3, pp. 193-199, 1995.

[54] E. A. Deitch, D. Xu, L. Franko, A. Ayala, and I. H. Chaudry, "Evidence favoring the role of the gut as a cytokinegenerating organ in rats subjected to hemorrhagic shock," Shock, vol. 1, no. 2, pp. 141-145, 1994.

[55] Y. Iimuro, R. M. Gallucci, M. I. Luster, H. Kono, and R. G. Thurman, "Antibodies to tumor necrosis factor $\alpha$ attenuate hepatic necrosis and inflammation caused by chronic exposure to ethanol in the rat," Hepatology, vol. 26, no. 6, pp. 1530-1537, 1997.

[56] N. Enomoto, K. Ikejima, B. U. Bradford et al., "Role of Kupffer cells and gut-derived endotoxins in alcoholic liver injury," Journal of Gastroenterology and Hepatology, vol. 15, pp. D20-D25, 2000.

[57] M. Yin, M. D. Wheeler, H. Kono et al., "Essential role of tumor necrosis factor $\alpha$ in alcohol-induced liver injury in mice," Gastroenterology, vol. 117, no. 4, pp. 942-952, 1999.

[58] R. Wiest, S. Das, G. Cadelina, G. Garcia-Tsao, S. Milstien, and R. J. Groszmann, "Bacterial translocation in cirrhotic rats stimulates eNOS-derived NO production and impairs mesenteric vascular contractility," Journal of Clinical Investigation, vol. 104, no. 9, pp. 1223-1233, 1999.

[59] A. Albillos, A. de la Hera, M. González et al., "Increased lipopolysaccharide binding protein in cirrhotic patients with marked immune and hemodynamic derangement," Hepatology, vol. 37, no. 1, pp. 208-217, 2003.

[60] H. Tilg, A. Wilmer, W. Vogel et al., "Serum levels of cytokines in chronic liver diseases," Gastroenterology, vol. 103, no. 1, pp. 264-274, 1992.

[61] C. Schafer, I. Schips, J. Landig, J. C. Bode, and C. Bode, "Tumor-necrosis-factor and interleukin-6 response of peripheral blood monocytes to low concentrations of lipopolysaccharide in patients with alcoholic liver disease," Zeitschrift fur Gastroenterologie, vol. 33, no. 9, pp. 503-508, 1995.

[62] J. Deviere, J. Content, C. Denys et al., "Immunoglobulin A and interleukin 6 form a positive secretory feedback loop: A study of normal subjects and alcoholic cirrhotics," Gastroenterology, vol. 103, no. 4, pp. 1296-1301, 1992.

[63] A. Khoruts, L. Stahnke, C. J. McClain, G. Logan, and J. I. Allen, "Circulating tumor necrosis factor, interleukin-1 and interleukin-6 concentrations in chronic alcoholic patients," Hepatology, vol. 13, no. 2, pp. 267-276, 1991.

[64] V. von Baehr, W. D. Döcke, M. Plauth et al., "Mechanisms of endotoxin tolerance in patients with alcoholic liver cirrhosis: role of interleukin 10, interleukin 1 receptor antagonist, and soluble tumour necrosis factor receptors as well as effector cell desensitisation," Gut, vol. 47, no. 2, pp. 281-287, 2000.

[65] C. C. Chan, S. J. Hwang, F. Y. Lee et al., "Prognostic value of plasma endotoxin levels in patients with cirrhosis," Scandinavian Journal of Gastroenterology, vol. 32, no. 9, pp. 942-946, 1997.

[66] S. M. Riordan, N. Skinner, A. Nagree et al., "Peripheral blood mononuclear cell expression of toll-like receptors and relation to cytokine levels in cirrhosis," Hepatology, vol. 37, no. 5, pp. 1154-1164, 2003.

[67] J. P. Visapää, J. Tillonen, and M. Salaspuro, "Microbes and mucosa in the regulation of intracolonic acetaldehyde concentration during ethanol challenge," Alcohol and Alcoholism, vol. 37, no. 4, pp. 322-326, 2002.
[68] C. Bode and J. C. Bode, "Effect of alcohol consumption on the gut," Bailliere's Best Practice and Research in Clinical Gastroenterology, vol. 17, no. 4, pp. 575-592, 2003.

[69] L. Ferrier, F. Bérard, L. Debrauwer et al., "Impairment of the intestinal barrier by ethanol involves enteric microflora and mast cell activation in rodents," American Journal of Pathology, vol. 168, no. 4, pp. 1148-1154, 2006.

[70] R. K. Rao, "Acetaldehyde-induced barrier disruption and paracellular permeability in Caco-2 cell monolayer," Methods in Molecular Biology, vol. 447, pp. 171-183, 2008.

[71] A. Parlesak, C. Schäfer, T. Schütz, J. C. Bode, and C. Bode, "Increased intestinal permeability to macromolecules and endotoxemia in patients with chronic alcohol abuse in different stages of alcohol-induced liver disease," Journal of Hepatology, vol. 32, no. 5, pp. 742-747, 2000.

[72] C. Bode and J. C. Bode, "Activation of the innate immune system and alcoholic liver disease: effects of ethanol per se or enhanced intestinal translocation of bacterial toxins induced by ethanol?" Alcoholism, vol. 29, no. 11, pp. 166S-171S, 2005.

[73] E. Seki, S. De Minicis, C. H. Österreicher et al., "TLR4 enhances TGF- $\beta$ signaling and hepatic fibrosis," Nature Medicine, vol. 13, no. 11, pp. 1324-1332, 2007.

[74] A. W. Yan, D. E. Fouts, J. Brandl et al., "Enteric dysbiosis associated with a mouse model of alcoholic liver disease," Hepatology, vol. 53, no. 1, pp. 96-105, 2011.

[75] J. C. Bode, C. Bode, R. Heidelbach et al., "Jejunal microflora in patients with chronic alcohol abuse," HepatoGastroenterology, vol. 31, no. 1, pp. 30-34, 1984.

[76] F. C. Morencos, G. de las Heras Castaño, L. Martín Ramos et al., "Small bowel bacterial overgrowth in patients with alcoholic cirrhosis," Digestive Diseases and Sciences, vol. 40, no. 6, pp. 1252-1256, 1995.

[77] T. Hauge, J. Persson, and D. Danielsson, "Mucosal bacterial growth in the upper gastrointestinal tract in alcoholics (heavy drinkers)," Digestion, vol. 58, no. 6, pp. 591-595, 1997.

[78] Y. Tang, C. B. Forsyth, A. Farhadi et al., "Nitric oxidemediated intestinal injury is required for alcohol-induced gut leakiness and liver damage," Alcoholism, vol. 33, no. 7, pp. 1220-1230, 2009.

[79] A. Keshavarzian, A. Farhadi, C. B. Forsyth et al., "Evidence that chronic alcohol exposure promotes intestinal oxidative stress, intestinal hyperpermeability and endotoxemia prior to development of alcoholic steatohepatitis in rats," Journal of Hepatology, vol. 50, no. 3, pp. 538-547, 2009.

[80] A. Banan, J. Z. Fields, H. Decker, Y. Zhang, and A. Keshavarzian, "Nitric oxide and its metabolites mediate ethanol-induced microtubule disruption and intestinal barrier dysfunction," Journal of Pharmacology and Experimental Therapeutics, vol. 294, no. 3, pp. 997-1008, 2000.

[81] A. Banan, A. Keshavarzian, L. Zhang et al., "NF- $\kappa$ B activation as a key mechanism in ethanol-induced disruption of the F-actin cytoskeleton and monolayer barrier integrity in intestinal epithelium," Alcohol, vol. 41, no. 6, pp. 447-460, 2007.

[82] G. Kolios, V. Valatas, and S. G. Ward, "Nitric oxide in inflammatory bowel disease: a universal messenger in an unsolved puzzle," Immunology, vol. 113, no. 4, pp. 427-437, 2004.

[83] T. R. Jerrells, D. Peritt, C. Marietta, and M. J. Eckardt, "Mechanisms of suppression of cellular immunity induced by ethanol," Alcoholism, vol. 13, no. 4, pp. 490-493, 1989.

[84] D. Sibley and T. R. Jerrells, "Alcohol consumption by C57BL/6 mice is associated with depletion of lymphoid cells from the gut-associated lymphoid tissues and altered 
resistance to oral infections with Salmonella typhimurium," Journal of Infectious Diseases, vol. 182, no. 2, pp. 482-489, 2000.

[85] A. S. Sozinov, "Systemic endotoxemia during chronic viral hepatitis," Bulletin of Experimental Biology and Medicine, vol. 133, no. 2, pp. 153-155, 2002.

[86] N. G. Sandler, C. Koh, A. Roque et al., "Host response to translocated microbial products predicts outcomes of patients with HBV or HCV infection," Gastroenterology, vol. 141, no. 4, pp. 1220-1230, 2011.

[87] G. Marchetti, P. Nasta, F. Bai et al., "Circulating sCD14 is associated with virological response to pegylated-interferon$\alpha$ /ribavirin treatment in HIV/HCV co-infected patients," PLoS ONE, vol. 7, no. 2, Article ID e32028, 2012.

[88] A. Balagopal, F. H. Philp, J. Astemborski et al., "Human immunodeficiency virus-related microbial translocation and progression of hepatitis C," Gastroenterology, vol. 135, no. 1, pp. 226-233, 2008.

[89] P. Brun, I. Castagliuolo, V. Di Leo et al., "Increased intestinal permeability in obese mice: new evidence in the pathogenesis of nonalcoholic steatohepatitis," American Journal of Physiology, vol. 292, no. 2, pp. G518-G525, 2007.

[90] A. Farhadi, S. Gundlapalli, M. Shaikh et al., "Susceptibility to gut leakiness: a possible mechanism for endotoxaemia in non-alcoholic steatohepatitis," Liver International, vol. 28, no. 7, pp. 1026-1033, 2008.

[91] L. Miele, V. Valenza, G. La Torre et al., "Increased intestinal permeability and tight junction alterations in nonalcoholic fatty liver disease," Hepatology, vol. 49, no. 6, pp. 1877-1887, 2009.

[92] A. J. Wigg, I. C. Roberts-Thomson, R. H. Grose, A. G. Cummins, R. B. Dymock, and P. J. McCarthy, "The role of small intestinal bacterial overgrowth, intestinal permeability, endotoxaemia, and tumour necrosis factor $\alpha$ in the pathogenesis of non-alcoholic steatohepatitis," Gut, vol. 48, no. 2, pp. 206211, 2001.

[93] P. D. Cani, R. Bibiloni, C. Knauf et al., "Changes in gut microbiota control metabolic endotoxemia-induced inflammation in high-fat diet-induced obesity and diabetes in mice," Diabetes, vol. 57, no. 6, pp. 1470-1481, 2008.

[94] P. D. Cani, J. Amar, M. A. Iglesias et al., "Metabolic endotoxemia initiates obesity and insulin resistance," Diabetes, vol. 56, no. 7, pp. 1761-1772, 2007.

[95] E. A. Griffiths, L. C. Duffy, F. L. Schanbacher et al., "In vivo effects of bifidobacteria and lactoferrin on gut endotoxin concentration and mucosal immunity in Balb/c mice," Digestive Diseases and Sciences, vol. 49, no. 4, pp. 579589, 2004.

[96] I. Bergheim, S. Weber, M. Vos et al., "Antibiotics protect against fructose-induced hepatic lipid accumulation in mice: role of endotoxin," Journal of Hepatology, vol. 48, no. 6, pp. 983-992, 2008.

[97] A. Spruss, G. Kanuri, S. Wagnerberger, S. Haub, S. C. Bischoff, and I. Bergheim, "Toll-like receptor 4 is involved in the development of fructose-induced hepatic steatosis in mice," Hepatology, vol. 50, no. 4, pp. 1094-1104, 2009.

[98] A. G. Ruiz, F. Casafont, J. Crespo et al., "Lipopolysaccharidebinding protein plasma levels and liver TNF- $\alpha$ gene expression in obese patients: evidence for the potential role of endotoxin in the pathogenesis of non-alcoholic steatohepatitis," Obesity Surgery, vol. 17, no. 10, pp. 1374-1380, 2007.

[99] H. Yoshida, T. Hamada, S. Inuzuka, T. Ueno, M. Sata, and K. Tanikawa, "Bacterial infection in cirrhosis, with and without hepatocellular carcinoma," American Journal of Gastroenterology, vol. 88, no. 12, pp. 2067-2071, 1993.

[100] M. Deschênes and J. P. Villeneuve, "Risk factors for the development of bacterial infections in hospitalized patients with cirrhosis," American Journal of Gastroenterology, vol. 94, no. 8, pp. 2193-2197, 1999.

[101] W. R. Caly and E. Strauss, "A prospective study of bacterial infections in patients with cirrhosis," Journal of Hepatology, vol. 18, no. 3, pp. 353-358, 1993.

[102] J. Fernández, M. Navasa, J. Gómez et al., "Bacterial infections in cirrhosis: epidemiological changes with invasive procedures and norfloxacin prophylaxis," Hepatology, vol. 35, no. 1, pp. 140-148, 2002.

[103] M. Borzio, F. Salerno, L. Piantoni et al., "Bacterial infection in patients with advanced cirrhosis: a multicentre prospective study," Digestive and Liver Disease, vol. 33, no. 1, pp. 41-48, 2001.

[104] B. Campillo, J. P. Richardet, T. Kheo, and C. Dupeyron, "Nosocomial spontaneous bacterial peritonitis and bacteremia in cirrhotic patients: impact of isolate type on prognosis and characteristics of infection," Clinical Infectious Diseases, vol. 35, no. 1, pp. 1-10, 2002.

[105] J. M. Llovet, P. Rodríguez-Iglesias, E. Mointinho et al., "Spontaneous bacterial peritonitis in patients with cirrhosis undergoing selective intestinal decontamination. A retrospective study of 229 spontaneous bacterial peritonitis episodes," Journal of Hepatology, vol. 26, no. 1, pp. 88-95, 1997.

[106] B. Campillo, C. Dupeyron, J. P. Richardet, N. Mangeney, and G. Leluan, "Epidemiology of severe hospital-acquired infections in patients with liver cirrhosis: effect of long-term administration of norfloxacin," Clinical Infectious Diseases, vol. 26, no. 5, pp. 1066-1070, 1998.

[107] M. Navasa and J. Rodés, "Bacterial infections in cirrhosis," Liver International, vol. 24, no. 4, pp. 277-280, 2004.

[108] F. C. Morencos, G. De las Heras Castano, L. M. Ramos, M. J. Lopez Arias, F. Ledesma, and F. P. Romero, "Small bowel bacterial overgrowth in patients with alcoholic cirrhosis," Digestive Diseases and Sciences, vol. 40, no. 6, pp. 1252-1256, 1995.

[109] T. M. Bauer, B. Steinbrückner, F. E. Brinkmann et al., "Small intestinal bacterial overgrowth in patients with cirrhosis: prevalence and relation with spontaneous bacterial peritonitis," American Journal of Gastroenterology, vol. 96, no. 10, pp. 2962-2967, 2001.

[110] A. Rimola, F. Bory, J. Teres et al., "Oral, nonabsorbable antibiotics prevent infection in cirrhotics with gastrointestinal hemorrhage," Hepatology, vol. 5, no. 3, pp. 463-467, 1985.

[111] G. Soriano, C. Guarner, A. Tomas et al., "Norfloxacin prevents bacterial infection in cirrhotics with gastrointestinal hemorrhage," Gastroenterology, vol. 103, no. 4, pp. 12671272, 1992.

[112] P. Gines, A. Rimola, R. Planas et al., "Norfloxacin prevents spontaneous bacterial peritonitis recurrence in cirrhosis: results of a double-blind, placebo-controlled trial," Hepatology, vol. 12, no. 4 I, pp. 716-724, 1990.

[113] J. D. Grangie, D. Roulot, G. Pelletier et al., "Norfloxacin primary prophylaxis of bacterial infections in cirrhotic patients with ascites: a double-blind randomized trial," Journal of Hepatology, vol. 29, no. 3, pp. 430-436, 1998.

[114] R. J. Groszmann, "Hyperdynamic circulation of liver disease 40 years later: pathophysiology and clinical consequences," Hepatology, vol. 20, no. 5, pp. 1359-1363, 1994. 
[115] R. Wiest and R. J. Groszmann, "The paradox of nitric oxide in cirrhosis and portal hypertension: too much, not enough," Hepatology, vol. 35, no. 2, pp. 478-491, 2002.

[116] P. Vallance and S. Moncada, "Hyperdynamic circulation in cirrhosis: a role for nitric oxide?" The Lancet, vol. 337, no. 8744, pp. 776-778, 1991.

[117] C. Guarner, G. Soriano, A. Tomas et al., "Increased serum nitrite and nitrate levels in patients with cirrhosis: relationship to endotoxemia," Hepatology, vol. 18, no. 5, pp. 11391143, 1993.

[118] C. J. Chu, F. Y. Lee, S. S. Wang et al., "Hyperdynamic circulation of cirrhotic rats with ascites: role of endotoxin, tumour necrosis factor- $\alpha$ and nitric oxide," Clinical Science, vol. 93, no. 3, pp. 219-225, 1997.

[119] J. C. Lopez-Talavera, G. Cadelina, J. Olchowski, W. Merrill, and R. J. Groszmann, "Thalidomide inhibits tumor necrosis factor $\alpha$, decreases nitric oxide synthesis, and ameliorates the hyperdynamic circulatory syndrome in portal-hypertensive rats," Hepatology, vol. 23, no. 6, pp. 1616-1621, 1996.

[120] B. Rasaratnam, D. Kaye, G. Jennings, F. Dudley, and J. P. F. Chin-Dusting, "The effect of selective intestinal decontamination on the hyperdynamic circulatory state in cirrhosis. A randomized trial," Annals of Internal Medicine, vol. 139, no. 3, pp. 186-193, 2003.

[121] U. Thalhieimer, C. K. Triantes, D. N. Samonakis, D. Patch, and A. K. Burroughs, "Infection, coagulation, and variceal bleeding in cirrhosis," Gut, vol. 54, no. 4, pp. 556-563, 2005.

[122] J. Goulis, D. Patch, and A. K. Burroughs, "Bacterial infection in the pathogenesis of variceal bleeding," The Lancet, vol. 353, no. 9147, pp. 139-142, 1999.

[123] P. Montalto, J. Vlachogiannakos, D. J. Cox, S. Pastacaldi, D. Patch, and A. K. Burroughs, "Bacterial infection in cirrhosis impairs coagulation by a heparin effect: a prospective study," Journal of Hepatology, vol. 37, no. 4, pp. 463-470, 2002.

[124] A. Plessier, M. H. Denninger, Y. Consigny et al., "Coagulation disorders in patients with cirrhosis and severe sepsis," Liver International, vol. 23, no. 6, pp. 440-448, 2003.

[125] C. Zhao, S. B. Chen, J. P. Zhou et al., "Prognosis of hepatic cirrhosis patients with esophageal or gastric variceal hemorrhage: multivariate analysis," Hepatobiliary and Pancreatic Diseases International, vol. 1, no. 3, pp. 416-419, 2002.

[126] J. Pohl, K. Pollmann, P. Sauer, A. Ring, W. Stremmel, and T. Schlenker, "Antibiotic prophylaxis after variceal hemorrhage reduces incidence of early rebleeding," HepatoGastroenterology, vol. 51, no. 56, pp. 541-546, 2004.

[127] S. Vivas, M. Rodriguez, M. A. Palacio, A. Linares, J. L. Alonso, and L. Rodrigo, "Presence of bacterial infection in bleeding cirrhotic patients is independently associated with early mortality and failure to control bleeding," Digestive Diseases and Sciences, vol. 46, no. 12, pp. 2752-2757, 2001.

[128] A. T. Blei and J. Córdoba, "Hepatic encephalopathy," American Journal of Gastroenterology, vol. 96, no. 7, pp. 1968-1976, 2001.

[129] A. Lemberg and M. A. Fernández, "Hepatic encephalopathy, ammonia, glutamate, glutamine and oxidative stress," Annals of Hepatology, vol. 8, no. 2, pp. 95-102, 2009.

[130] C. Yurdaydin, T. J. Walsh, H. D. Engler et al., "Gut bacteria provide precursors of benzodiazepine receptor ligands in a rat model of hepatic encephalopathy," Brain Research, vol. 679, no. 1, pp. 42-48, 1995.

[131] D. F. Schafer, J. M. Fowler, and E. A. Jones, "Colonic bacteria: a source of $\gamma$-aminobutyric acid in blood," Proceedings of the Society for Experimental Biology and Medicine, vol. 167, no. 3, pp. 301-303, 1981.
[132] R. Avallone, M. L. Zeneroli, I. Venturini et al., "Endogenous benzodiazepine-like compounds and diazepam binding inhibitor in serum of patients with liver cirrhosis with and without overt encephalopathy," Gut, vol. 42, no. 6, pp. 861867, 1998.

[133] K. D. Mullen, K. M. Szauter, and K. Kaminsky-Russ, "'Endogenous' benzodiazepine activity in body fluids of patients with hepatic encephalopathy," The Lancet, vol. 336, no. 8707, pp. 81-83, 1990.

[134] L. Leger, J. P. Lenriot, M. Fourestier, and B. Goiffon, "The role of total colectomy in portacaval encephalopathy," Journal de Chirurgie, vol. 103, no. 5, pp. 437-450, 1972.

[135] W. V. McDermott, M. Victor, and W. W. Point, "Exclusion of the colon in the treatment of hepatic encephalopathy,", The New England Journal of Medicine, vol. 267, no. 17, pp. 850854, 1962.

[136] M. L. Chapman and H. D. Janowitz, "Chronic portalsystemic encephalopathy after ileostomy and colonic resection," The Lancet, vol. 1, no. 7446, pp. 1064-1065, 1966.

[137] A. Rabiller, H. Nunes, D. Lebrec et al., "Prevention of Gramnegative translocation reduces the severity of hepatopulmonary syndrome," American Journal of Respiratory and Critical Care Medicine, vol. 166, no. 4, pp. 514-517, 2002.

[138] C. Guarner, B. A. Runyon, M. Heck, S. Young, and M. Y. Sheikh, "Effect of long-term trimethoprim-sulfamethoxazole prophylaxis on ascites formation, bacterial translocation, spontaneous bacterial peritonitis, and survival in cirrhotic rats," Digestive Diseases and Sciences, vol. 44, no. 10, pp. 19571962, 1999.

[139] B. A. Runyon, M. Borzio, S. Young, S. U. Squier, C. Guarner, and M. A. Runyon, "Effect of selective bowel decontamination with norfloxacin on spontaneous bacterial peritonitis, translocation, and survival in an animal model of cirrhosis," Hepatology, vol. 21, no. 6, pp. 1719-1724, 1995.

[140] M. Novella, R. Solà, G. Soriano et al., "Continuous versus inpatient prophylaxis of the first episode of spontaneous bacterial peritonitis with norfloxacin," Hepatology, vol. 25, no. 3, pp. 532-536, 1997.

[141] B. Campillo, C. Dupeyron, and J. P. Richardet, "Epidemiology of hospital-acquired infections in cirrhotic patients: effect of carriage of methicillin-resistant Staphylococcus aureus and influence of previous antibiotic therapy and norfloxacin prophylaxis," Epidemiology and Infection, vol. 127, no. 3, pp. 443-450, 2001.

[142] S. L. Gorbach, "Probiotics and gastrointestinal health," American Journal of Gastroenterology, vol. 95, no. 1, pp. S2S4, 2000 .

[143] A. F. Mattar, R. A. Drongowski, A. G. Coran, and C. M. Harmon, "Effect of probiotics on enterocyte bacterial translocation in vitro," Pediatric Surgery International, vol. 17, no. 4, pp. 265-268, 2001.

[144] R. Wiest, F. Chen, G. Cadelina, R. J. Groszmann, and G. Garcia-Tsao, "Effect of Lactobacillus-fermented diets on bacterial translocation and intestinal flora in experimental prehepatic portal hypertension," Digestive Diseases and Sciences, vol. 48, no. 6, pp. 1136-1141, 2003.

[145] T. M. Bauer, J. Fernández, M. Navasa, J. Vila, and J. Rodés, "Failure of Lactobacillus spp. to prevent bacterial translocation in a rat model of experimental cirrhosis," Journal of Hepatology, vol. 36, no. 4, pp. 501-506, 2002.

[146] C. B. Forsyth, A. Farhadi, S. M. Jakate, Y. Tang, M. Shaikh, and A. Keshavarzian, "Lactobacillus GG treatment ameliorates alcohol-induced intestinal oxidative stress, gut 
leakiness, and liver injury in a rat model of alcoholic steatohepatitis," Alcohol, vol. 43, no. 2, pp. 163-172, 2009.

[147] M. Chiva, G. Soriano, I. Rochat et al., "Effect of Lactobacillus johnsonii Lal and antioxidants on intestinal flora and bacterial translocation in rats with experimental cirrhosis," Journal of Hepatology, vol. 37, no. 4, pp. 456-462, 2002.

[148] Z. Li, S. Yang, H. Lin et al., "Probiotics and antibodies to TNF inhibit inflammatory activity and improve nonalcoholic fatty liver disease," Hepatology, vol. 37, no. 2, pp. 343-350, 2003.

[149] R. Xu, Y. Wan, Q. Fang et al., "Supplementation with probiotics modifies gut flora and attenuates liver fat accumulation in rat nonalcoholic fatty liver disease model," Journal of Clinical Biochemistry and Nutrition, vol. 50, no. 1, pp. 72-77, 2012.

[150] X. Ma, J. Hua, and Z. Li, "Probiotics improve high fat dietinduced hepatic steatosis and insulin resistance by increasing hepatic NKT cells," Journal of Hepatology, vol. 49, no. 5, pp. 821-830, 2008.

[151] E. Esposito, A. Iacono, G. Bianco et al., "Probiotics reduce the inflammatory response induced by a high-fat diet in the liver of young rats," Journal of Nutrition, vol. 139, no. 5, pp. 905-911, 2009.

[152] A. Velayudham, A. Dolganiuc, M. Ellis et al., "VSL\#3 probiotic treatment attenuates fibrosis without changes in steatohepatitis in a diet-induced nonalcoholic steatohepatitis model in mice," Hepatology, vol. 49, no. 3, pp. 989-997, 2009.

[153] C. Loguercio, A. Federico, C. Tuccillo et al., "Beneficial effects of a probiotic VSL\#3 on parameters of liver dysfunction in chronic liver diseases," Journal of Clinical Gastroenterology, vol. 39, no. 6, pp. 540-543, 2005.

[154] J. Lata, I. Novotný, V. Př́bramská et al., “The effect of probiotics on gut flora, level of endotoxin and ChildPugh score in cirrhotic patients: results of a double-blind randomized study," European Journal of Gastroenterology and Hepatology, vol. 19, no. 12, pp. 1111-1113, 2007.

[155] Q. Liu, Z. P. Duan, D. K. Ha, S. Bengmark, J. Kurtovic, and S. M. Riordan, "Synbiotic modulation of gut flora: effect on minimal hepatic encephalopathy in patients with cirrhosis," Hepatology, vol. 39, no. 5, pp. 1441-1449, 2004.

[156] D. Pereg, A. Kotliroff, N. Gadoth, R. Hadary, M. Lishner, and Y. Kitay-Cohen, "Probiotics for patients with compensated liver cirrhosis: a double-blind placebo-controlled study," Nutrition, vol. 27, no. 2, pp. 177-181, 2011.

[157] N. Rayes, D. Seehofer, S. Hansen et al., "Early enteral supply of Lactobacillus and fiber versus selective bowel decontamination: a controlled trial in liver transplant recipients," Transplantation, vol. 74, no. 1, pp. 123-127, 2002.

[158] N. Rayes, D. Seehofer, T. Theruvath et al., "Supply of pre- and probiotics reduces bacterial infection rates after liver transplantation-a randomized, double-blind trial," American Journal of Transplantation, vol. 5, no. 1, pp. 125130, 2005.

[159] C. Chen, L. Li, Z. Wu, H. Chen, and S. Fu, "Effects of lactitol on intestinal microflora and plasma endotoxin in patients with chronic viral hepatitis," Journal of Infection, vol. 54, no. 1, pp. 98-102, 2007.

[160] K. F. Kummel and S. Brokx, "Lactitol as a functional prebiotic," Cereal Foods World, vol. 46, no. 9, pp. 424-429, 2001.

[161] O. Riggio, M. Varriale, G. P. Testore et al., "Effect of lactitol and lactulose administration on the fecal flora in cirrhotic patients," Journal of Clinical Gastroenterology, vol. 12, no. 4, pp. 433-436, 1990.
[162] K. J. Foster, S. Lin, and C. J. Turck, "Current and emerging strategies for treating hepatic encephalopathy," Critical Care Nursing Clinics of North America, vol. 22, no. 3, pp. 341-350, 2010.

[163] C. Loguercio, R. Abbiati, M. Rinaldi, A. Romano, C. Del Vecchio Blanco, and M. Coltorti, "Long-term effects of Enterococcus faecium SF68 versus lactulose in the treatment of patients with cirrhosis and grade 1-2 hepatic encephalopathy," Journal of Hepatology, vol. 23, no. 1, pp. 39-46, 1995.

[164] M. Malaguarnera, F. Greco, G. Barone, M. P. Gargante, M. Malaguarnera, and M. A. Toscano, "Bifidobacterium longum with fructo-oligosaccharide (FOS) treatment in minimal hepatic encephalopathy: a randomized, double-blind, placebo-controlled study," Digestive Diseases and Sciences, vol. 52, no. 11, pp. 3259-3265, 2007.

[165] J. S. Bajaj, K. Saeian, K. M. Christensen et al., "Probiotic yogurt for the treatment of minimal hepatic encephalopathy," American Journal of Gastroenterology, vol. 103, no. 7, pp. 1707-1715, 2008.

[166] V. V. Mittal, B. C. Sharma, P. Sharma, and S. K. Sarin, "A randomized controlled trial comparing lactulose, probiotics, and L-ornithine L-aspartate in treatment of minimal hepatic encephalopathy," European Journal of Gastroenterology and Hepatology, vol. 23, no. 8, pp. 725-732, 2011. 

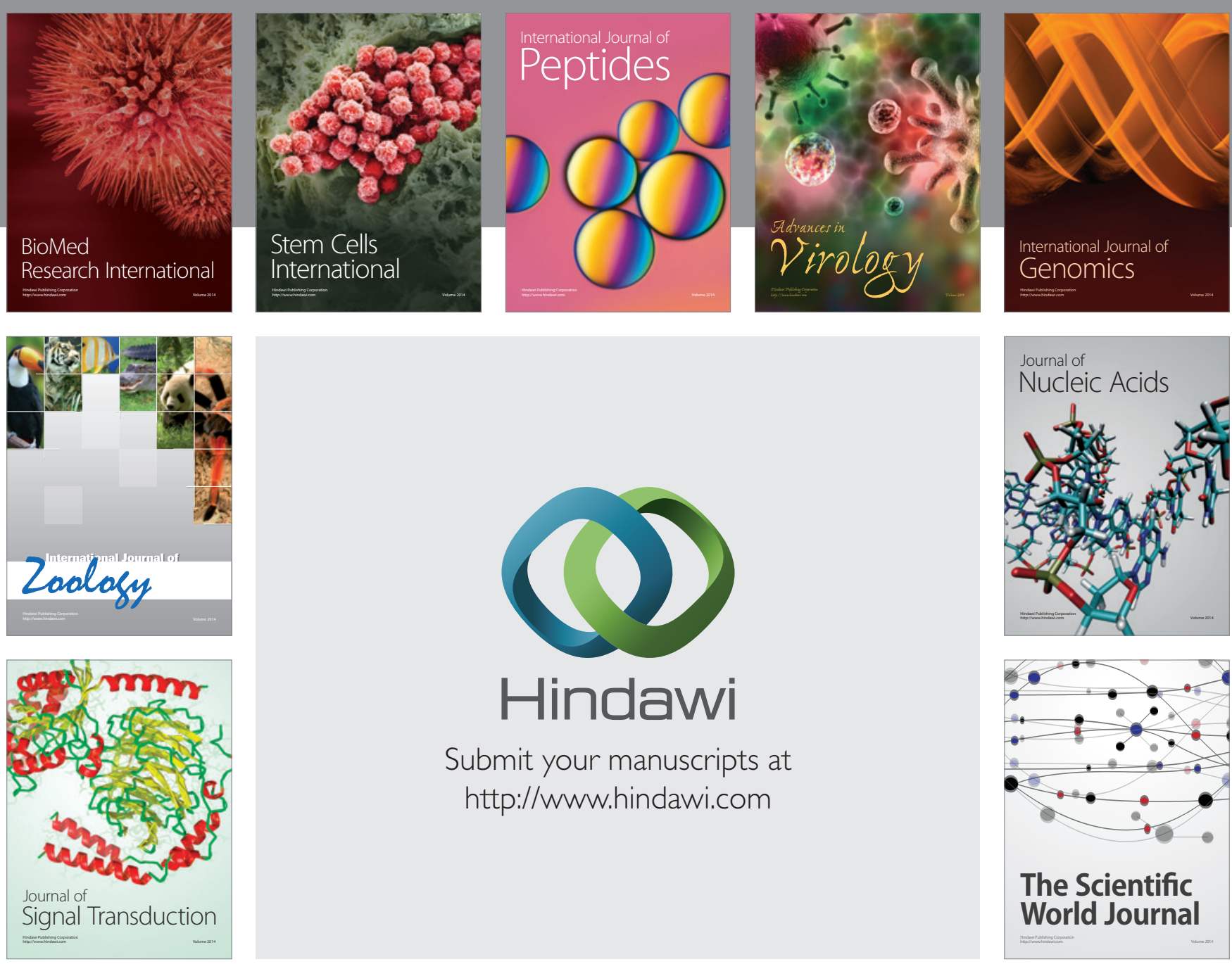

Submit your manuscripts at

http://www.hindawi.com
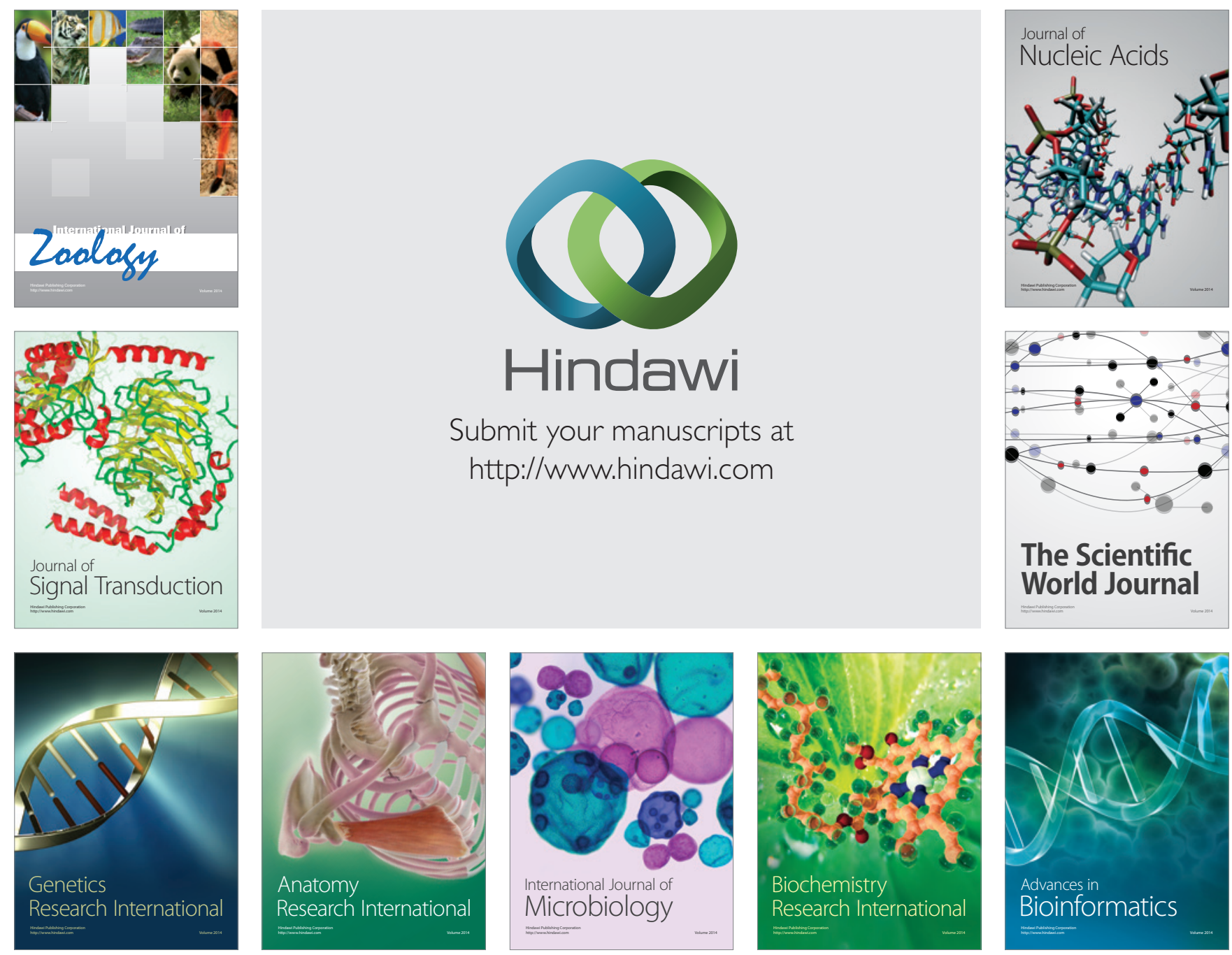

The Scientific World Journal
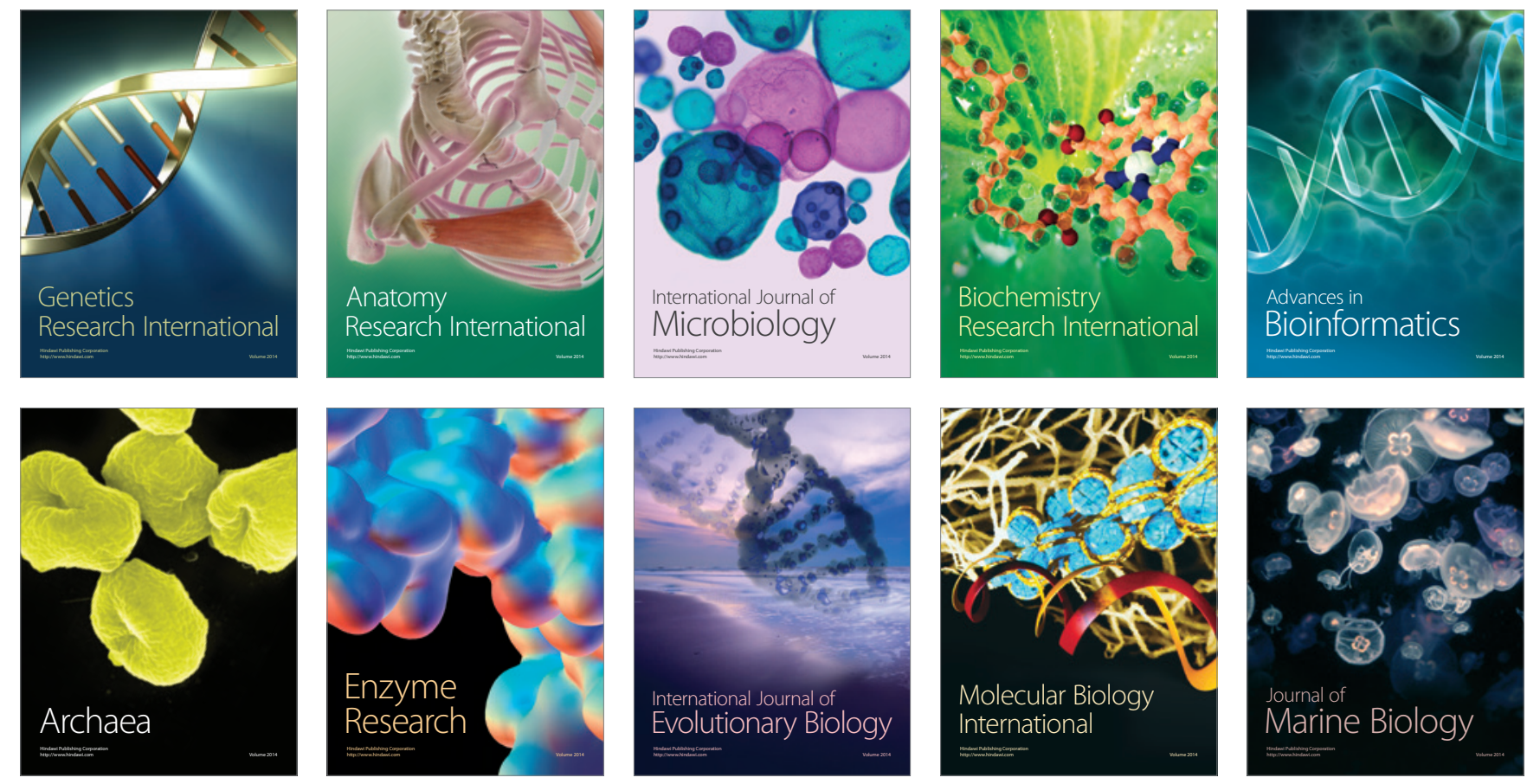